\title{
Corrigendum: Mobile money and regional financial integration: Evidence from sub-Saharan Africa
}

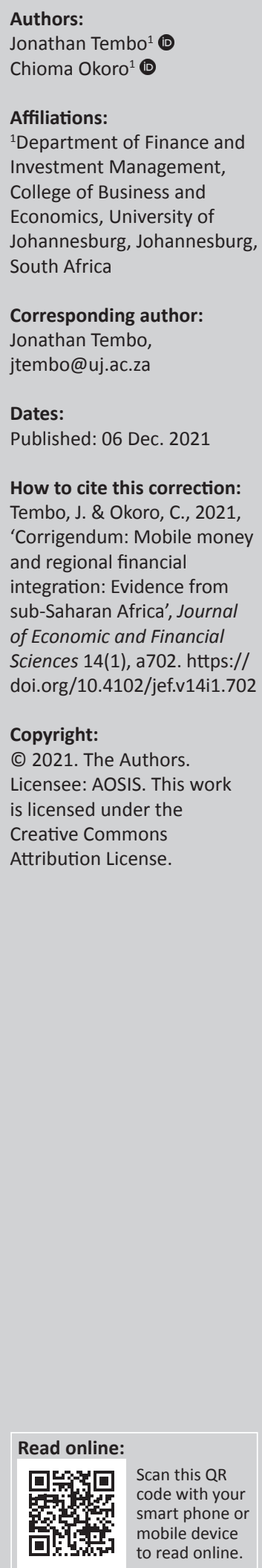

In the version of this article initially published, Tembo, J. \& Okoro, C., 2021, 'Mobile money and regional financial integration: Evidence from sub-Saharan Africa', Journal of Economic and Financial Sciences 14(1), a655. https://doi.org/10.4102/jef.v14i1.655, the authors' affiliation was given incorrectly in the 'Affiliations' sections. The correct affiliation should be 'Department of Finance and Investment Management, College of Business and Economics, University of Johannesburg, Johannesburg, South Africa' instead of 'Department of Finance and Investment, College of Business and Economics, University of Johannesburg, Johannesburg, South Africa'.

This correction does not alter the study's findings of significance or overall interpretation of the study's results. The authors apologise for any inconvenience caused. 